Providence College

DigitalCommons@Providence

2012

Characterization of a Reductively-Activated Elimination Pathway

Relevant to the Biological Chemistry of the Kinamycins and

Lomaiviticins

\author{
Seann P. Mulcahy \\ Providence College, smulcahy@providence.edu \\ Christina M. Woo \\ Weidong Ding
}

George A. Ellestad

Seth B. Herzon

Follow this and additional works at: https://digitalcommons.providence.edu/chemistry_fac

Part of the Chemistry Commons

Mulcahy, Seann P.; Woo, Christina M.; Ding, Weidong; Ellestad, George A.; and Herzon, Seth B., "Characterization of a Reductively-Activated Elimination Pathway Relevant to the Biological Chemistry of the Kinamycins and Lomaiviticins" (2012). Chemistry \& Biochemistry Faculty Publications. 1.

https://digitalcommons.providence.edu/chemistry_fac/1

This Article is brought to you for free and open access by the Chemistry \& Biochemistry at DigitalCommons@Providence. It has been accepted for inclusion in Chemistry \& Biochemistry Faculty Publications by an authorized administrator of DigitalCommons@Providence. For more information, please contact dps@providence.edu. 


\title{
Characterization of a reductively-activated elimination pathway relevant to the biological chemistry of the kinamycins and lomaiviticins $\dagger$
}

\author{
Seann P. Mulcahy, ${ }^{a}$ Christina M. Woo, ${ }^{a}$ Weidong Ding, ${ }^{b}$ George A. Ellestad $^{c}$ and Seth B. Herzon ${ }^{* a}$ \\ Received 27th October 2011, Accepted 2nd December 2011 \\ DOI: $10.1039 / \mathrm{c} 2 \mathrm{sc00854h}$
}

The lomaiviticins (1 and 2) and kinamycins (3-5) are bacterial metabolites with potent antimicrobial and antiproliferative activities. Herein we establish that 1-5 are capable of generating electrophilic acylfulvene intermediates (6) under mildly reducing conditions. These acylfulvenes $\mathbf{6}$ are formed by a multistep process comprising two-electron reduction and loss of dinitrogen to form an ortho-quinone methide, followed by elimination. Based on these studies, the structure of the product formed from $\mathbf{1}$ in DNA-cleavage assays is proposed (26). We also show that the bis(hydroxynaphthoquinone) substructures of the lomaiviticins activate the metabolites toward reduction. Finally, based on COMPARE and time-dependent cell response profiling analyses, we show that kinamycin C (4) and the monomeric lomaiviticin aglycon (24) operate by a mechanism of action that is distinct from simple diazofluorenes, such as $\mathbf{2 3}$.

\section{Introduction}

The quinone methide occupies an eminent position in nature's molecular arsenal. Frequently, this functional group behaves as

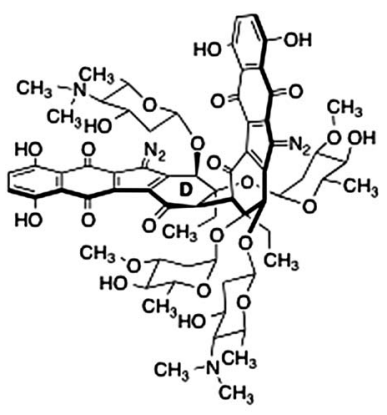

(-)-Iomaiviticin A (1)
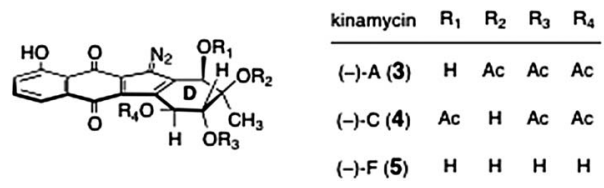

${ }^{a}$ Department of Chemistry, Yale University, New Haven, Connecticut, USA. E-mail: seth.herzon@yale.edu; Fax: +1-203-432-6144; Tel: +1203-436-8571

${ }^{b}$ Pfizer Central Research, Groton, CT, 06340, USA

'Department of Chemistry, Columbia University, New York, NY, 10027 $\dagger$ Electronic supplementary information (ESI) available: Experimental procedures and detailed characterization data of all new compounds. See DOI: $10.1039 / \mathrm{c} 2 \mathrm{sc} 00854 \mathrm{~h}$ a powerful electrophile, and this reactivity forms the basis for the cytotoxicity of many natural products and drugs. ${ }^{1}$ Here we present evidence that the diazobenzo $[b]$ fluorene (diazofluorene) antitumor antibiotics the lomaiviticins ( $\mathbf{1}$ and $\mathbf{2})^{2}$ and the kinamycins (3-5) $)^{3}$ form quinone methides which do not react by nucleophilic addition but instead undergo an elimination reaction to produce electrophilic acylfulvene intermediates (see 6, Fig. 1a). ${ }^{4}$ This mode of reactivity was first postulated by Moore over 30 years ago for the kinamycins, ${ }^{5}$ but experimental evidence for its feasibility has not been reported, so far as we are aware.

The cellular target(s) of the lomaiviticins and kinamycins are currently not known. Members of both classes of metabolites have been reported to cleave dsDNA in the presence of a reducing co-factor in vitro ${ }^{2,6}$ and in tissue culture. ${ }^{7}$ Hasinoff and Dmitrienko have also provided evidence that kinamycin $\mathrm{F}$

a.
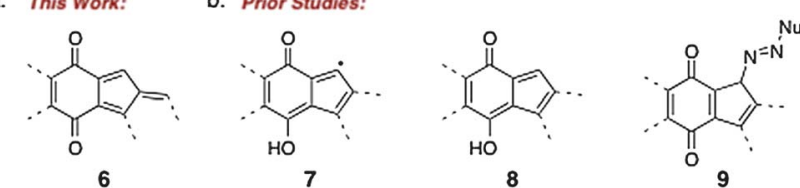

c.
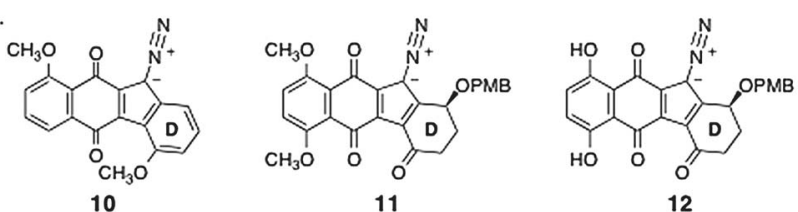

Fig. 1 (a) Acylfulvene intermediate (6) implicated by this work. (b) Intermediates (7-9) previously proposed to form from the kinamycins and lomaiviticins. (c) Structure of a model diazofluorene previously studied (10) and the diazofluorenes used in this work $(\mathbf{1 1}, \mathbf{1 2})$. 
(5) targets a protein in the cyclic D3 production pathway. ${ }^{8}$ The structural dissimilarities between 1, 2 and 3-5 also raise the possibility that different mechanisms of action are operative. ${ }^{9}$

Several studies aimed at elucidating the chemical behaviour of diazofluorenes have been described. ${ }^{10}$ These findings established the high reactivity of this functional group toward reducing agents and nucleophiles. Based on these prior results, several reaction manifolds have been proposed to underlie the cytotoxic effects of 1-5. These include intracellular reduction to form vinyl radicals (7, Fig. 1b) ${ }^{6,10 b-d}$ and quinone methide intermediates (8) ${ }^{6,10 b-f}$ nucleophilic attack to produce covalent adducts such as $9,{ }^{10 b}$ and generation of reactive oxygen species by redox cycling of the quinone. ${ }^{6 b, 7}$ All in vitro mechanistic studies have employed substrates which contain an aromatic D-ring, such as dimethylprekinamycin (10, Fig. 1c).

\section{Results}

Our studies have focused on the diazofluorenes 11 and 12, which contain an ether substituent on the D-ring (Fig. 1c). The diazofluorene $\mathbf{1 1}$ was prepared according to the sequence outlined in Scheme $1 .{ }^{11}$ The synthesis began with 4-(S)-[(4-methoxybenzyl) oxy]cyclohex-2-ene-1-one (13), ${ }^{12}$ which was homologated to the $\beta$-(trimethylsilylmethyl)cyclohexenone $\mathbf{1 4}$ by a three-step sequence ( $49 \%$ overall). Fluoride-mediated coupling of $\mathbf{1 4}$ with 2,3-dibromo-5,8-dimethoxynaphthoquinone then formed the $\gamma$ alkylation product $15(87 \%)$. Cyclization of $\mathbf{1 5}$, mediated by palladium acetate in the presence of silver carbonate, generated the ortho-quinone methide $16(62 \%)$. Finally, diazo transfer to the ortho-quinone methide $\mathbf{1 6}$ produced the synthetic diazofluorene $\mathbf{1 1}$ in $97 \%$ yield.<smiles>O=C1C=CC(O[18O])CC1</smiles>

13<smiles>CC(C)C</smiles>

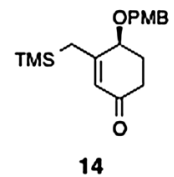

14

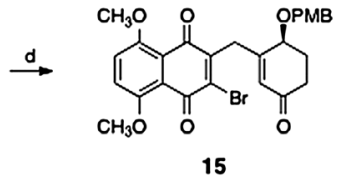

le

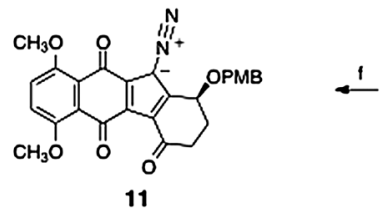

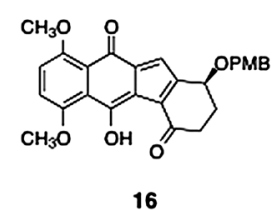

Scheme 1 Synthesis of the diazofluorene 11: Reagents and conditions: (a) $\mathrm{TMSCH}_{2} \mathrm{MgCl}, \mathrm{CuI}$, THF, $-60^{\circ} \mathrm{C}$, then HMPA, Et ${ }_{3} \mathrm{~N}, \mathrm{TMSCl},-60 \rightarrow$ $24{ }^{\circ} \mathrm{C}$; (b) $\mathrm{PhSeCl}, \mathrm{THF},-78{ }^{\circ} \mathrm{C}, 78 \%$ (two steps); (c) $\mathrm{H}_{2} \mathrm{O}_{2}, \mathrm{CH}_{2} \mathrm{Cl}_{2}, 24$ ${ }^{\circ} \mathrm{C}$, 63\%; (d) 2,3-dibromo-5,8-dimethoxynaphthoquinone, TASF(Et), THF, $-78{ }^{\circ} \mathrm{C}, 87 \%$; (e) $\mathrm{Pd}(\mathrm{OAc})_{2}$, polymer-supported triphenylphosphine, $\mathrm{Ag}_{2} \mathrm{CO}_{3}$, toluene, $80{ }^{\circ} \mathrm{C}, 62 \%$; (f) $\mathrm{TfN}_{3}, \mathrm{Et}_{3} \mathrm{~N}, \mathrm{CH}_{3} \mathrm{CN}, 0{ }^{\circ} \mathrm{C}, 97 \%$.

We found that the diazofluorene $\mathbf{1 1}$ was indefinitely stable as a solid or in solutions of aprotic, non-nucleophilic solvents at ambient temperature. In contrast, under mildly reducing conditions in protic solvents $\mathbf{1 1}$ reacted rapidly (Scheme 2). Thus, treatment of a methanolic solution of $\mathbf{1 1}$ with dithiothreitol $(\mathrm{DTT} ; \mathbf{1 1}]=[\mathrm{DTT}]=20 \mathrm{mM})$ and warming to $37^{\circ} \mathrm{C}$ produced the methoxy-substituted ortho-quinone methide 17. In a preparative-scale experiment, $\mathbf{1 7}$ was obtained in $80 \%$ isolated yield after $24 \mathrm{~h}$. The experiments outlined below establish that the pathway from $\mathbf{1 1}$ to $\mathbf{1 7}$ comprises: (1) reduction of the diazo function of 11 to form the ortho-quinone methide 16; (2) elimination of para-methoxybenzyl alcohol from $\mathbf{1 6}$ to generate the acylfulvene intermediate 18; (3) 1,6-addition of methanol to 18 to provide the methyl ether product 17.

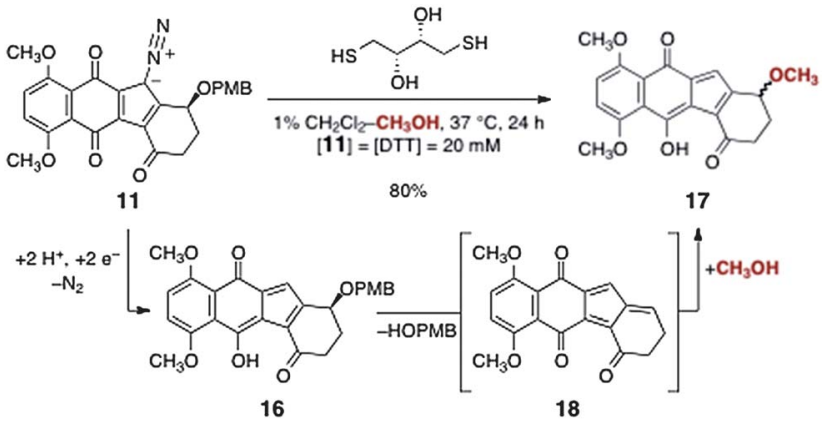

Scheme 2 Reduction-solvolysis of the diazofluorene $\mathbf{1 1 .}$

The following lines of evidence support this reaction pathway. First, we found that the diazofluorene $\mathbf{1 1}$ was stable for at least $24 \mathrm{~h}$ in methanol, which argues against direct $\mathrm{S}_{\mathrm{N}} 2$ displacement of para-methoxybenzyl alcohol from 11. Second, LC/MS monitoring of the reduction-solvolysis confirmed that the orthoquinone methide $\mathbf{1 6}$ was formed; at $30 \%$ conversion of $\mathbf{1 1}$, the ratio of $\mathbf{1 1}$ to $\mathbf{1 6}$ was $\sim 3: 1$ (Fig. 2). Since the ortho-quinone methide $\mathbf{1 6}$ is the penultimate synthetic precursor to the diazofluorene 11 (Scheme 1), we were able to unequivocally establish its presence in solution by LC/MS co-injection with an authentic sample. Circular dichroism (CD) analysis of isolated $\mathbf{1 7}$ revealed that it was optically inactive, supporting the generation of an achiral intermediate, such as 18. Finally, monitoring the reduction-solvolysis of $\mathbf{1 1}$ simultaneously by LC/MS and CD analysis established a correlation between conversion to $\mathbf{1 7}$ and loss of optical activity, indicating that neither $\mathbf{1 1}$ nor $\mathbf{1 6}$ racemize under the reaction conditions (see ESI $\dagger$ ).

We also studied the solvolysis of the isolated quinone methide 16 directly $(\mathbf{1 6} \rightarrow \mathbf{1 7})$. Under neutral conditions in methanol at

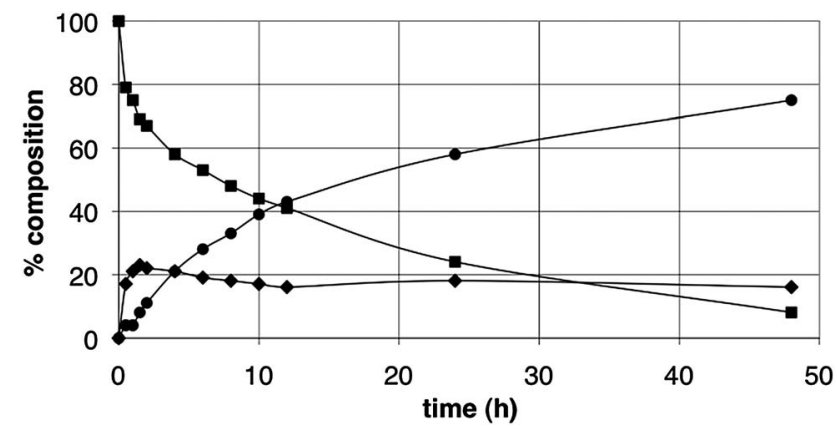

Fig. 2 Reduction-solvolysis of the diazofluorene 11: (घ) diazofluorene 11, $(\diamond)$ ortho-quinone methide 16, $(\bullet)$ methyl ether 17. Reagents and conditions: $11(200 \mu \mathrm{M})$, DTT $(200 \mu \mathrm{M}), 1 \% \mathrm{CH}_{2} \mathrm{Cl}_{2}-\mathrm{CH}_{3} \mathrm{OH}, 37^{\circ} \mathrm{C}$. 

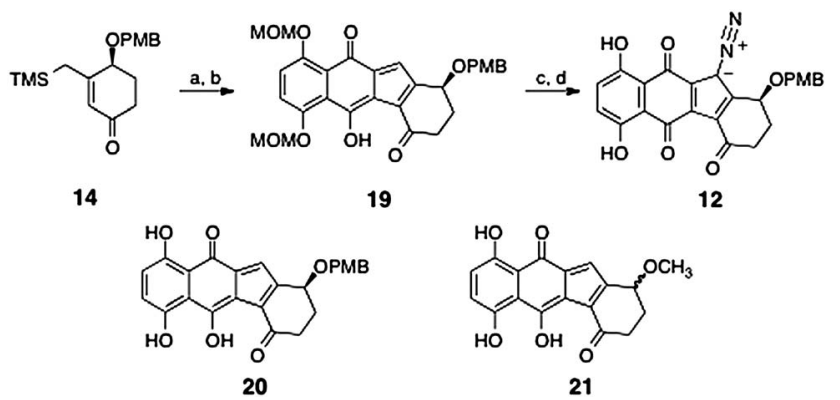

19

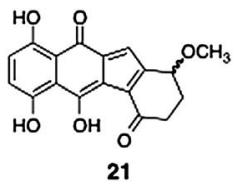

Scheme 3 Synthesis of the diazofluorene 12 and structures of the orthoquinone methides $\mathbf{2 0}$ and 21. Reagents and conditions: (a) 2,3-dibromo5,8-bis(methoxymethyloxy)naphthoquinone, TASF(Et), $\mathrm{CH}_{2} \mathrm{Cl}_{2},-78$ ${ }^{\circ} \mathrm{C}, 99 \%$; (b) $\mathrm{Pd}(\mathrm{OAc})_{2}$, polymer-supported triphenylphosphine, $\mathrm{Ag}_{2} \mathrm{CO}_{3}$, toluene, $80{ }^{\circ} \mathrm{C}, 33 \%$; (c) $\mathrm{TfN}_{3}, \mathrm{Et}_{3} \mathrm{~N}, \mathrm{CH}_{3} \mathrm{CN}, 0{ }^{\circ} \mathrm{C}, 71 \%$; (d) $\mathrm{HCl}-$ $\mathrm{CH}_{3} \mathrm{OH},-78 \rightarrow-20{ }^{\circ} \mathrm{C}, 59 \%$.

$37^{\circ} \mathrm{C}$, the half-life for solvolysis was $10 \mathrm{~h}$, and in a preparativescale experiment, 17 was isolated in 96\% yield (see ESI $\dagger$ ). Addition of trichloroacetic acid ( 1 equiv) decreased the half-life for solvolysis to $2.4 \mathrm{~h}$, whereas addition of triethylamine (1 equiv) increased the half-life of $\mathbf{1 6}$ to approximately $51 \mathrm{~h}$. Under strongly basic conditions (1 equiv sodium methoxide), the solvolysis occurred smoothly, albeit more slowly, with a half-life of $161 \mathrm{~h}$.

To gain insight into the effects of the phenol substituents of the lomaiviticins on this reduction-elimination pathway, we prepared the bis(hydroxy)diazofluorene 12 (Scheme 3). Analogous to the bis(methyl ether) 11, treatment of 12 with DTT in methanol formed the expected ortho-quinone methide (20) and solvolysis (21) products. Although the intermediates in this series showed partial decomposition after $4 \mathrm{~h}$ in solution, this experiment revealed that $\mathbf{1 2}$ is reduced three-fold faster than $\mathbf{1 1}(60 \%$ conversion of $\mathbf{1 2}$ and $21 \%$ conversion of $\mathbf{1 1}$ after $30 \mathrm{~min}$, see $\mathrm{ESI} \dagger$ ). This enhanced reactivity suggests that the phenol substituents of the lomaiviticins activate the metabolites for reduction. ${ }^{13}$

To translate our findings to phenotype-based assays, we assessed the antiproliferative properties of diazofluorenes 11 and 12, the simpler constructs 22 and $\mathbf{2 3},{ }^{\mathbf{1 4}}$ the monomeric lomaiviticin aglycon $\mathbf{2 4},{ }^{11 b}$ the ortho-quinone methide 16, and kinamycin $\mathrm{C}(\mathbf{4}$, Table 1$) .{ }^{15}$ Our results establish that analogs bearing free phenols are more potent than those with aryl methyl ethers (compare $\mathbf{1 2}$ to 11), possibly due to the increased rate of reduction of the former. Furthermore, the presence of a reductively-labile oxygen substituent on the D-ring leads to an approximately two-fold increase in activity (12 vs. 22). Surprisingly, however, certain analogs possessing a D-ring with a quaternary center (23) exhibited high potency, suggesting that mechanisms other than reductive activation may contribute to these molecules' cytotoxic effects. These assays also show that isolated ortho-quinone methides such as $\mathbf{1 6}$ are inactive. This may be due to rapid degradation in cell culture; less than $40 \%$ of 16 remained after warming to $37^{\circ} \mathrm{C}$ for $15 \mathrm{~h}$ in $\mathrm{LNCaP}$ cell lysate.

We generated time-dependent cell response profiles (TCRPs) by measuring cell culture impedance as a function of time for kinamycin $\mathrm{C}(\mathbf{4})$, the diazofluorene $\mathbf{2 3}$, and the monomeric lomaiviticin aglycon 24, employing the A172 cell line. This technique has previously been used to assess similarities between natural products' mechanisms of action. ${ }^{16}$ As shown in Fig. 3, the TCRPs of kinamycin $\mathrm{C}$ (4) and the monomeric lomaiviticin aglycon $\mathbf{2 4}$ are similar but distinct from the diazofluorene 23. Moreover, a COMPARE analysis of the anticancer activities of $\mathbf{2 3}^{\mathbf{1 7}}$ and kinamycin C (4) in the NCI 60-cell line panel ${ }^{18}$ reveals a poor correlation $(r=0.527) .{ }^{19}$ These data show that these diazofluorenes operate by distinct or multiple mechanisms of action.

\section{Discussion}

The experiments outlined above demonstrate that the lomaiviticins and kinamycins undergo reduction to ortho-quinone methide products under biologically-relevant conditions. Although such intermediates were generated in earlier studies, ${ }^{10 c, d, f}$ these experiments were conducted under abiotic conditions (catalytic hydrogenation or tributyltin hydride/ AIBN) and employed planar, aromatic substrates, such as prekinamycin dimethyl ether (10). By using the more functionalized substrates 11 and 12, we have revealed that the D-ring of these metabolites is reactive as well. The chemistry we have observed was first proposed by Moore in $1977,{ }^{5}$ but has not been evaluated experimentally.

In the early 1990s, it was shown that various glycosylated anthracyclines undergo reduction followed by expulsion of an aminosugar residue to form vinylogous ortho-quinone methide intermediates. ${ }^{20}$ The experiments described herein suggest that the lomaiviticins follow a similar pattern of reactivity. Moreover, ESI/MS analysis of DNA-cleavage assays, employing lomaiviticin A (1) and DTT as reductant, revealed a product consistent with loss of dinitrogen and an aminosugar residue, and incorporation of one equivalent each of dihydrogen and methanol. ${ }^{21}$ However, the complexity of lomaiviticin A (1) and small sample size prevented rigorous determination of the structure at that time. In light of our observations, we propose the structure of this product as the methyl ether $\mathbf{2 6}$ (Scheme 4), and suggest $\mathbf{2 6}$ is formed by reduction-elimination to the acylfulvene $\mathbf{2 5}$, followed by 1,6 -addition of methanol. ${ }^{22}$

Our cell viability data suggest multiple mechanisms of action underlie the biological activity of synthetic diazofluorenes. Specifically, analogs such as $\mathbf{2 3}$, which do not contain a reductively-labile D-ring substituent, retain potent cytotoxic properties, but clearly operate by a mechanism of action that is distinct from those that do, such as kinamycin $\mathrm{C}$ (4) and the monomeric lomaiviticin aglycon 24. In retrospect this is not surprising; several quinone-based anticancer agents, such as the mitomycins and anthracyclines, ${ }^{20,23}$ manifest two or more chemical pathways that contribute to cytotoxicity, although in the case of the mitomycins, cross-linking of DNA is of the greatest biological significance. Finally, the inactivity of isolated ortho-quinone methides (e.g., 16) suggests reduction occurs after cellular entry and/or binding of the diazofluorenes to their target(s). An alternative interpretation of this result is that cytotoxicity arises directly from the diazofluorene itself. ${ }^{10 b}$ However, the different TCRPs of $\mathbf{4}$ and $\mathbf{2 4}$ compared to 23, as well as our COMPARE analysis, argue against this. 
Table $1 \quad \mathrm{LC}_{50}$ data $(\mu \mathrm{M})$ of kinamycin $\mathrm{C}(\mathbf{4})$ and selected analogs
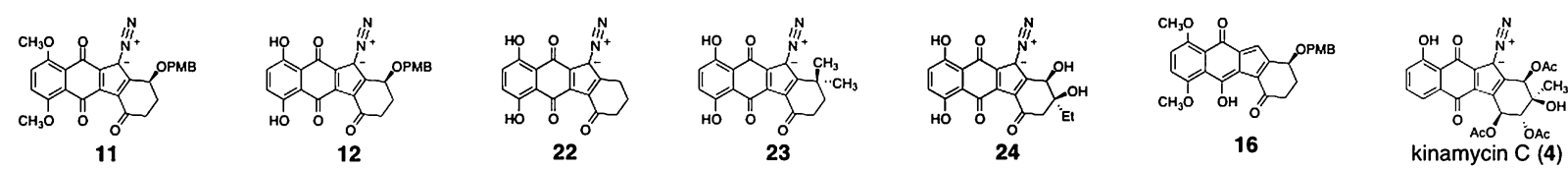

Cell line

\begin{tabular}{|c|c|c|c|c|c|c|c|}
\hline $\mathrm{HeLa}$ & 3.3 & 1.9 & 4.1 & 1.9 & 0.383 & $>10$ & 0.423 \\
\hline K562 & 1.5 & 0.99 & 1.5 & 0.015 & 0.124 & $>10$ & 0.091 \\
\hline $\mathrm{LNCaP}$ & 6.2 & 2.7 & 6.9 & 1.1 & 0.528 & $>10$ & 0.370 \\
\hline НCТ-116 & 4.9 & 1.7 & 5.0 & 0.484 & 0.230 & $>10$ & 0.643 \\
\hline
\end{tabular}

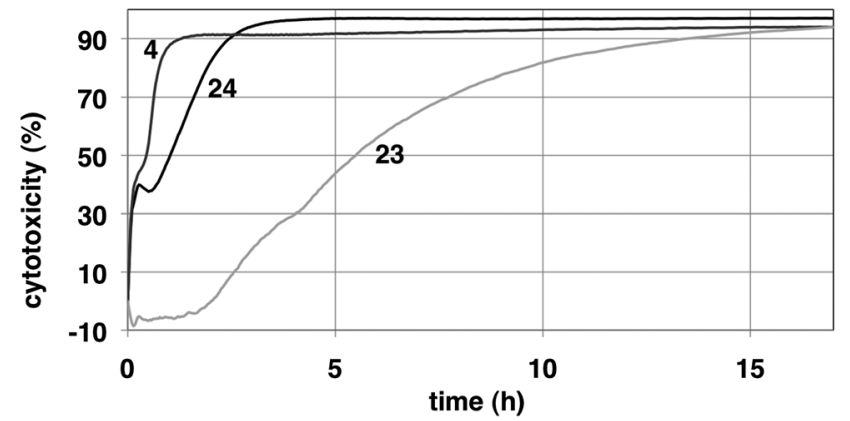

Fig. 3 Cytotoxicity (\%) of A172 cells on treatment with $10 \mu \mathrm{M}$ kinamycin $\mathrm{C}(\mathbf{4})$, the monomeric lomaiviticin aglycon $\mathbf{2 4}$, and the diazofluorene 23.
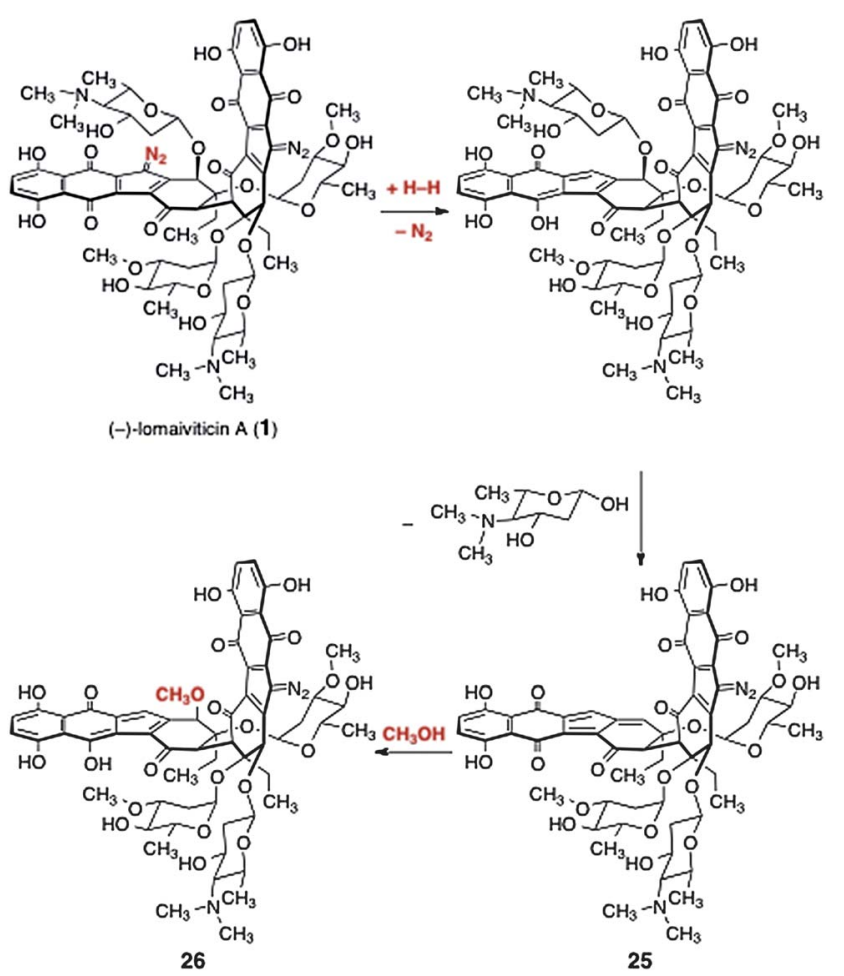

Scheme 4 Proposed reaction pathway for lomaiviticin A (1) under reducing conditions, in the presence of methanol.

\section{Conclusion}

Our studies have established a reductively-activated elimination pathway for the lomaiviticins and kinamycins and allow us to provide a plausible structure for the product formed from lomaiviticin A (1) in DNA-cleavage assays. Although the primary mechanism of action of $\mathbf{1}$ and $\mathbf{2}$ has yet to be established, the mild conditions and time-scale within which reduction and solvolysis occur suggest that this pathway is viable in tissue culture. Additionally, our structure-function studies reveal an activating role for the hydroxy groups of the lomaiviticins and show that isolated ortho-quinone methides (e.g., 16) are unstable under cellular conditions. Delineating the significance of these various pathways and intermediates as they relate to the observed cytotoxic effects of the lomaiviticins will be the focus of future research.

\section{Acknowledgements}

We thank Mr. Patrick McEnaney for valuable assistance with TCRP experiments. Financial support from the American Cancer Society, the National Science Foundation (Graduate Research Fellowship to C. M. W.), the Searle Scholars program, and Yale University is gratefully acknowledged.

\section{Notes and references}

1 For reviews, see: (a) D. C. Thompson, J. A. Thompson, M. Sugumaran and P. Moldéus, Chem.-Biol. Interact., 1993, 86, 129; (b) S. E. Wolkenberg and D. L. Boger, Chem. Rev., 2002, 102, 2477.

2 H. He, W. D. Ding, V. S. Bernan, A. D. Richardson, C. M. Ireland, M. Greenstein, G. A. Ellestad and G. T. Carter, J. Am. Chem. Soc., $2001,123,5362$.

3 (a) S. Ito, T. Matsuya, S. Ömura, M. Otani and A. Nakagawa, $J$. Antibiot., 1970, 23, 315; (b) T. Hata, S. Ömura, Y. Iwai, A. Nakagawa and M. Otani, J. Antibiot., 1971, 24, 353; (c) S. Omura, A. Nakagawa, H. Yamada, T. Hata, A. Furusaki and T. Watanabe, Chem. Pharm. Bull., 1971, 19, 2428; (d) S. Ōmura, A. Nakagawa, H. Yamada, T. Hata and A. Furusaki, Chem. Pharm. Bull., 1973, 21, 931; (e) M. C. Cone, P. J. Seaton, K. A. Halley and S. J. Gould, J. Antibiot., 1989, 42, 179; $(f)$ P. J. Seaton and S. J. Gould, J. Antibiot., 1989, 42, 189.

4 For reviews of the kinamycins and lomaiviticins, see: (a) S. J. Gould, Chem. Rev., 1997, 97, 2499; (b) J. Marco-Contelles and M. T. Molina, Curr. Org. Chem., 2003, 7, 1433; (c) D. P. Arya, Top. Heterocycl. Chem., 2006, 2, 129; (d) C. C. Nawrat and C. J. Moody, Nat. Prod. Rep., 2011, 28, 1426; (e) S. B. Herzon and C. M. Woo, Nat. Prod. Rep., 2012, 29, 87.

5 H. W. Moore, Science, 1977, 197, 527. 
6 (a) T. E. Ballard and C. Melander, Tetrahedron Lett., 2008, 49, 3157; (b) C. L. Heinecke and C. Melander, Tetrahedron Lett., 2010, 51, 1455.

7 K. A. O'Hara, X. Wu, D. Patel, H. Liang, J. C. Yalowich, N. Chen, V. Goodfellow, O. Adedayo, G. I. Dmitrienko and B. B. Hasinoff, Free Radical Biol. Med., 2007, 43, 1132.

8 K. A. O’Hara, G. I. Dmitrienko and B. B. Hasinoff, Chem.-Biol. Interact., 2010, 184, 396.

9 The glycoside residues and dimeric structures of the lomaiviticins may modify their mechanism of action, relative to the kinamycins. In a compelling study by Thorson and co-workers, synthetic colchicine glycoconjugates were shown to stabilize tubulin polymerization, while colchicine itself inhibits tubulin polymerization; see: A. Ahmed, N. R. Peters, M. K. Fitzgerald, J. A. Watson, Jr., F. M. Hoffmann and J. S. Thorson, J. Am. Chem. Soc., 2006, 128, 14224.

10 (a) D. P. Arya and D. J. Jebaratnam, J. Org. Chem., 1995, 60, 3268; (b) R. S. Laufer and G. I. Dmitrienko, J. Am. Chem. Soc., 2002, 124, 1854; (c) K. S. Feldman and K. J. Eastman, J. Am. Chem. Soc., 2005, 127, 15344; (d) K. S. Feldman and K. J. Eastman, J. Am. Chem. Soc., 2006, 128, 12562; (e) W. Zeng, T. E. Ballard, A. G. Tkachenko, V. A. Burns, D. L. Feldheim and C. Melander, Bioorg. Med. Chem. Lett., 2006, 16, 5148; (f) O. Khdour and E. B. Skibo, Org. Biomol. Chem., 2009, 7, 2140.
11 (a) C. M. Woo, L. Lu, S. L. Gholap, D. R. Smith and S. B. Herzon, J. Am. Chem. Soc., 2010, 132, 2540; (b) S. B. Herzon, L. Lu, C. M. Woo and S. L. Gholap, J. Am. Chem. Soc., 2011, 133, 7260.

12 (a) J. E. Audia, L. Boisvert, A. D. Patten, A. Villalobos and S. J. Danishefsky, J. Org. Chem., 1989, 54, 3738; (b) C. F. Nising, U. K. Ohnemueller and S. Braese, Synthesis, 2006, 2643.

13 For a discussion of substituent effects on the reduction of anthraquinones, see: R. L. Blankespoor, E. L. Kosters, A. J. Post and D. P. Van Meurs, J. Org. Chem., 1991, 56, 1609.

14 See ESI $\dagger$ for the syntheses of 22 and $\mathbf{2 3}$.

15 Kinamycin C (4, NSC 138425) was obtained from the NCI/DTP Open Chemical Repository (http://dtp.cancer.gov).

16 Y. A. Abassi, B. Xi, W. Zhang, P. Ye, S. L. Kirstein, M. R. Gaylord, S. C. Feinstein, X. Wang and X. Xu, Chem. Biol., 2009, 16, 712.

17 C. M. Woo and S. B. Herzon, unpublished results.

18 M. R. Boyd and K. D. Paull, Drug Dev. Res., 1995, 34, 91.

19 Generally, compounds with high Pearson coefficients operate by similar mechanisms of action, see ref. 18.

20 For a review, see: G. Gaudiano and T. H. Koch, Chem. Res. Toxicol., 1991, 4, 2.

21 W. Ding, unpublished results.

22 The stereochemistry of the methyl ether function of $\mathbf{2 6}$ is unknown and is arbitrarily depicted.

23 M. Tomasz, Chem. Biol., 1995, 2, 575. 